\title{
Treatment Techniques on Aluminum to Modify the Surface Wetting Properties
}

\author{
L. TORRISI* AND C. SCOLARO \\ Dipartimento di Fisica e S.d.T., V. le F.S. D'Alcontres 31, 98166 S. Agata, Messina, Italy \\ (Received October 19, 2014; in final form May 21, 2015)
}

\begin{abstract}
Different techniques of surface treatment are employed to modify the physical properties of aluminum surfaces. Experimental data report measurements of water wetting ability in aluminum surfaces treated with six different techniques: polishing, sanding, acid attach, laser ablation, ion implantation and nanoparticle deposition. Surfaces can be modified as a function of the different treatment parameters. Treatment duration, roughness and morphology play an important role in determining the properties from hydrophobic to hydrophilic behavior.
\end{abstract}

DOI: $10.12693 /$ APhysPolA.128.48

PACS: 68.35.B-, 81.65.-b, 46.55.+d

\section{Introduction}

Different chemical and physical treatments can be employed to modify the wetting ability of Al surfaces, such as thermal oxidation, mechanical rolling, ion implantation, laser ablation, and chemical etching. In this study the wet ability of the $\mathrm{Al}$ surface as a function of different treatments is investigated and discussed.

Aluminum is a soft and ductile metal, with a white color; it is the third most abundant element in the Earth crust; it is highly reactive and generally is found as aluminum oxides and sulfates. It has a low density of $2.7 \mathrm{~g} / \mathrm{cm}^{3}$, a melting point of $660^{\circ} \mathrm{C}$, a thermal conductivity of $237 \mathrm{~W} / \mathrm{mK}$, an electrical resistivity at room temperature of $28 \mathrm{n} \Omega \mathrm{m}$, a Mohs hardness of 2.75 and a Young's modulus of $70 \mathrm{GPa}$ [1]. It is able to resist to corrosion due to the phenomenon of oxygen passivation. The excellent corrosion resistance is due to a thin surface layer of $\mathrm{Al}_{2} \mathrm{O}_{3}$ that forms when the metal is exposed to air. The corrosion resistance is also often greatly reduced by aqueous salts, particularly in the presence of dissimilar metals. Structural components made from aluminum and its alloys are vital to the aerospace industry and are important in other areas of transportation and structural materials. The aluminum coverage of different materials is used as anti-corrosion of surfaces. Aluminum foil is widely regarded as the most effective material in flexible packaging, giving almost perfect protection against light and suppressing any transport of matter through the film. A polished film of aluminum serves as a good reflector (approximately 92\%) of visible light and an excellent reflector (as much as 98\%) of medium and far infrared radiation [2].

Aluminum can be used in several fields: transportation (automobiles, aircraft, railway, bicycles, etc.), packaging, building construction (windows, doors, etc.), household

*corresponding author; e-mail: lorenzo.torrisi@unime.it items (cooking utensils), electronics (transmission lines, substrate materials, LED support, etc.), chemistry, optical coating and mirrors.

The wet ability of $\mathrm{Al}$ surface is important for all of these applications, such as the request of hydrophobic (contact angle higher than $90^{\circ}$ ) $\mathrm{Al}$ surfaces for food container, the hydrophilic (contact angle lower than $90^{\circ}$ ) surfaces for $\mathrm{Al}-\mathrm{Al}$ and $\mathrm{Al}-$ other materials welding and interface preparation [3].

\section{Experimental section}

Experiments were conducted on pristine aluminium obtained by mechanical rolling to a final thickness of $300 \mu \mathrm{m}$ characterized by a mean roughness of $0.1 \mu \mathrm{m}$.

In these investigations six treatments were studied to modify the surface wetting ability. They are based on: polishing, sandblasting, chemical etching, laser ablation, ion implantation and deposition of metallic nanoparticles on the surface.

The polishing was obtained mechanically with highspeed rotary polisher up to obtain a mirror finished surface; the sandblasting was used with $10 \mu \mathrm{m}$ sized silica powder fluxed by air at about $100 \mathrm{~m} / \mathrm{s}$ final velocity; chemical etching was obtained using $\mathrm{HCl}$ at $10 \%$ concentration in water deposited for a fixed time on the surface followed by water removing; for the laser ablation experiments, an Nd:YAG laser operating at $1064 \mathrm{~nm}$ wavelength, $200 \mathrm{~mJ}$ maximum pulse energy, $3 \mathrm{~ns}$ pulse duration, $10 \mathrm{~Hz}$ repetition rate and $1 \mathrm{~cm}^{2}$ spot surface; ion implantation uses $2 \mathrm{keV} \mathrm{Ar}^{+}$ions at $20 \mu \mathrm{A}$ current emitted by an ion gun. $\mathrm{Ti}, \mathrm{Cu}, \mathrm{Ag}$ and $\mathrm{Au}$ nanoparticles with 50-100 nm in diameter and a concentration of $5 \mathrm{mg} / 10 \mathrm{ml}$ in water have been deposited as water drops on the Al samples. Nanoparticles were obtained by laser ablation of the different elements in water at the Laser Laboratory of Plasma Physics of Messina University.

The method used for the measurement of the contact angles is the "sessile drop" method which involves the measurement of the profile of a drop of liquid resting on a solid surface [4]. It consists essentially in the measure 
of the contact angle between the tangent to the profile of a distilled water drop, deposited on the sample surface, and the surface itself. The contact angles of liquid droplets $(1 \mu \mathrm{l}$ water deposited on the surface by means of a micro-liter syringe) were measured directly using a webcam aligned to the eyepiece of an optical microscope that records video and captures photos of the system formed by the solid sample (housed in a movable sample holder) and the liquid drop. Suitable software permits to measure the contact angle using the line fitting the surface level and the line tangent to the deposited drop in the initial curvature points from the horizontal surface. The contact angle measurement is performed 10 times before to give the average final value. Generally measurements are affected by an error of about $10 \%$.

The roughness measurements were performed using a Tencor P-10 surface profiler using a micrometric mobile tip with $1 \mathrm{mg}$ force scanning the sample surface. The system has a $10 \mathrm{~nm}$ depth resolution and $1 \mu \mathrm{m}$ lateral resolution during the scanning of the sample surface. The surface roughness was measured using the average peak-topeak distance of the roughness profile.

Scanning electron microscopy (SEM) was performed by using a $20 \mathrm{keV}$ electron beam produced by a Fei Quanta - model Inspect S microscope at the Physics Department of Messina University.

The evaluation on the ion range and sputtering yield due to the Ar ion implantation treatment was obtained using the international SRIM Code of Ziegler [5].

\section{Results}

Polishing treatment. The process used to polish aluminum has to match the amount of tarnish and roughness of a given surface removing the hard oxidized aluminum patina. Mechanical polishing techniques using hard abrasives tend to scratch, smear, or even embed abrasive particles in the material surface [6]. We have adopted abrasive silicate grains from micrometric to sub-micrometric sized dispersed in a chemical-mechanical polishing solution employed to polish optical components. The polishing of Al surface prolonger for some hours has transformed it in a very reflective surface becoming it so as a mirror. Figure 1 shows a comparison of a SEM image in pristine (a) and polished surface (b). The same figure shows the typical roughness profile in the pristine (c) and polished (d) surface, valuated of $0.1 \mu \mathrm{m}$ and $0.028 \mu \mathrm{m}$, respectively. In the figure bottom it is possible to observe the photo comparison between the water drop on the pristine (e) and on the polished surface (f). The measured contact angle at room temperature was $95^{\circ}$ and $99^{\circ}$ for pristine and polished surface, respectively. Thus the treatment increases the contact angle enhancing the hydrophobicity of the Al surface.

Sandblasting treatment. The sandblasting process has been obtained spraying $\mathrm{SiO}_{2}$ micrometric particles, less than $10 \mu \mathrm{m}$ in diameter, against the Al surface in air [7]. The abrasive microparticles were accelerated by a fast
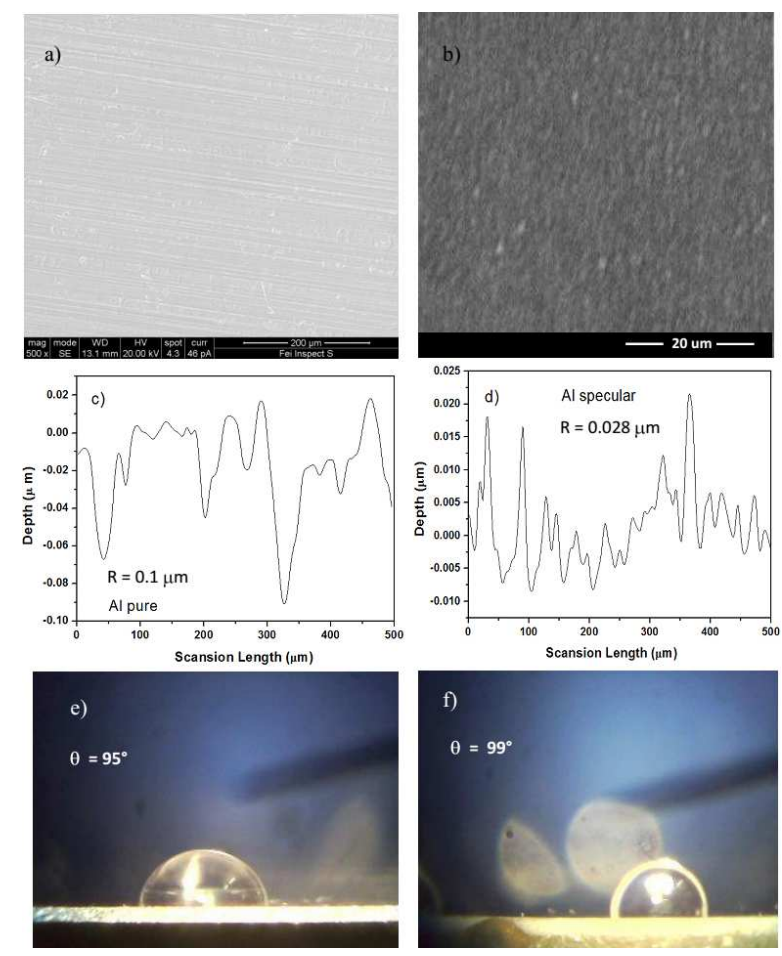

Fig. 1. Comparison of a SEM image in pristine (a) and polished surface (b), typical roughness profile in the pristine (c) and polished (d) surface, and comparison between the water drop photo on the pristine (e) and on the polished surface (f).

nitrogen flux to about $100 \mathrm{~m} / \mathrm{s}$ and they hit the substrate orthogonally to its surface. The treatment time was varied from $30 \mathrm{~s}$ up to $3 \mathrm{~min}$ and a surface cleaning in high pressure air was performed at the end of the process. Figure 2 shows a comparison between the SEM images of an Al surface treated using sandblasting for $30 \mathrm{~s}$ (a) and $3 \mathrm{~min}$ (b), their profile of surface roughness at $1 \mathrm{~min}(\mathrm{c})$ and $3 \mathrm{~min}(\mathrm{~d})$ and the optical images of the water drop for minor (d) and prolonger treatment (e) from which it is possible to measure the wetting ability. The average roughness is $3 \mu \mathrm{m}$ and $4.5 \mu \mathrm{m}$ for $30 \mathrm{~s}$ and 3 min sandblasting, respectively, while the contact angle from the initial $95^{\circ}$ measured in the pristine surface decreases to $85^{\circ}$ at $30 \mathrm{~s}$ sandblasting treatment and up to $63^{\circ}$ at 3 min sandblasting, demonstrating that the long treatment increases the hydrophilicity of the Al surface.

Chemical etching treatment. $\mathrm{HCl}$ at $10 \%$ in water volume was deposited on the Al surface at room temperature $\left(22^{\circ} \mathrm{C}\right)$ for different times from $30 \mathrm{~s}$ up to $10 \mathrm{~min}$ and just after removed with water. The reactions

$$
\begin{aligned}
& 2 \mathrm{Al}+6 \mathrm{HCl} \rightarrow 2 \mathrm{AlCl}_{3}+3 \mathrm{H}_{2} ; \\
& \mathrm{Al}_{2} \mathrm{O}_{3}+6 \mathrm{HCl} \rightarrow 2 \mathrm{AlCl}_{3}+3 \mathrm{H}_{2} \mathrm{O}
\end{aligned}
$$

may occur at the surface, removing the aluminium oxide and the first Al layers [8]. The surface is chemically etched in preferential points from which the reactions start to diffuse superficially. Figure 3 shows a typical SEM image, of the centres of initial chemical attaches, 

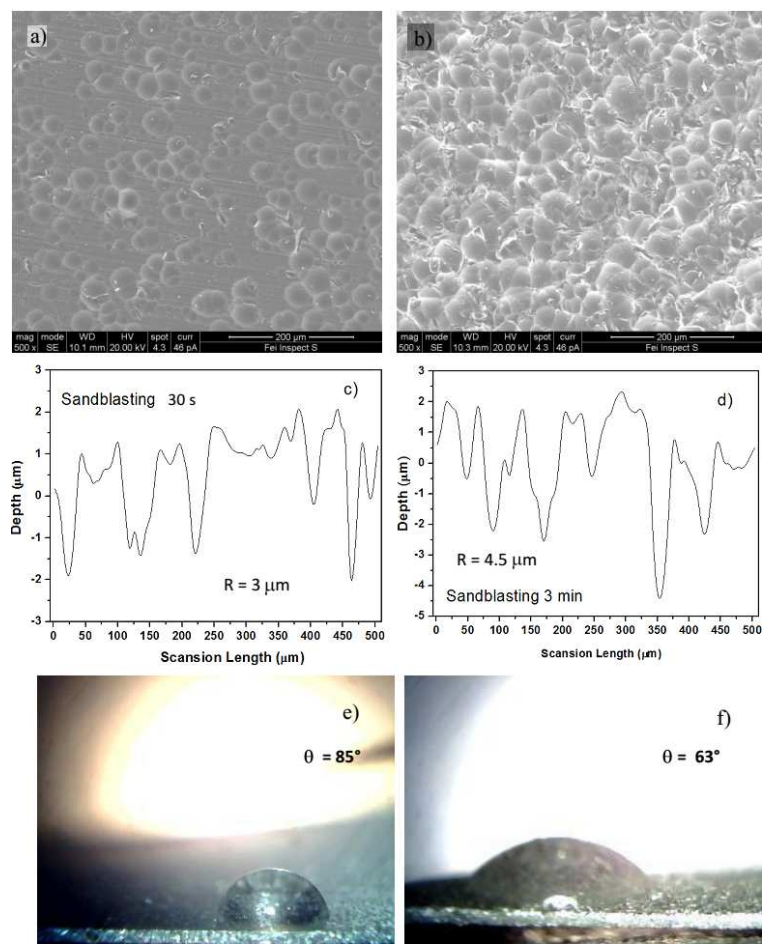

Fig. 2. Comparison between the SEM images of an Al surface treated using sandblasting for $30 \mathrm{~s}$ (a) and $3 \mathrm{~min}(\mathrm{~b})$, the profile of surface roughness at $30 \mathrm{~s} \mathrm{(c)}$ and $3 \mathrm{~min}(\mathrm{~d})$ and the optical images of the water drop for the minor (d) and the prolonger treatment (e).

obtained in the first $60 \mathrm{~s}$ (a) and of their progression after 3 min (b). The same figure shows the surface roughness profile which is about $3 \mu \mathrm{m}$ (c) and $6 \mu \mathrm{m}$ (d) in the two cases, respectively. The wet ability of the two cases is observable from the photos reported in Fig. 3e and f, indicating a contact angle decreasing to $75^{\circ}$ and $13^{\circ}$ at $1 \mathrm{~min}$ and $3 \mathrm{~min} \mathrm{HCl}$ etching. Thus this treatment induces high hydrophilicity of the $\mathrm{Al}$ surface.

Laser ablation treatment. The $1064 \mathrm{~nm}$ laser radiation without any focalization on the Al surface, with a spot of $1 \mathrm{~cm}^{2}$ and $10 \mathrm{~Hz}$ repetition rate, produces removing of the first superficial layers as a function of the pulse energy and of the irradiation time [9]. The ablated surface shows more roughness with respect to the pristine one. Figure 4 shows a SEM comparison of the ablated surface due to 50 laser shots at $50 \mathrm{~mJ}$ (a) and $200 \mathrm{~mJ}$ (b) pulse energy, the corresponding surface roughness was evaluated to $0.7 \mu \mathrm{m}$ (c) and $0.8 \mu \mathrm{m}$ (d), respectively. The figure shows also the comparison of the optical images of the drop wetting ability for the low energy irradiation (e) and high energy irradiation (f), at which the contact angle is $92^{\circ}$ and $45^{\circ}$ for low and high laser energy, respectively, both using an irradiation with 50 laser shots. Results indicate that low laser energy may decrease the contact angle from the pristine value of $95^{\circ}$ up to about $92^{\circ}$ (using 50 laser shots at pulse energy of $50 \mathrm{~mJ}$ ); at high laser energy and high shots number $(\approx 1000)$ the contact angle decreases up to $45^{\circ}$ showing that the laser treatment
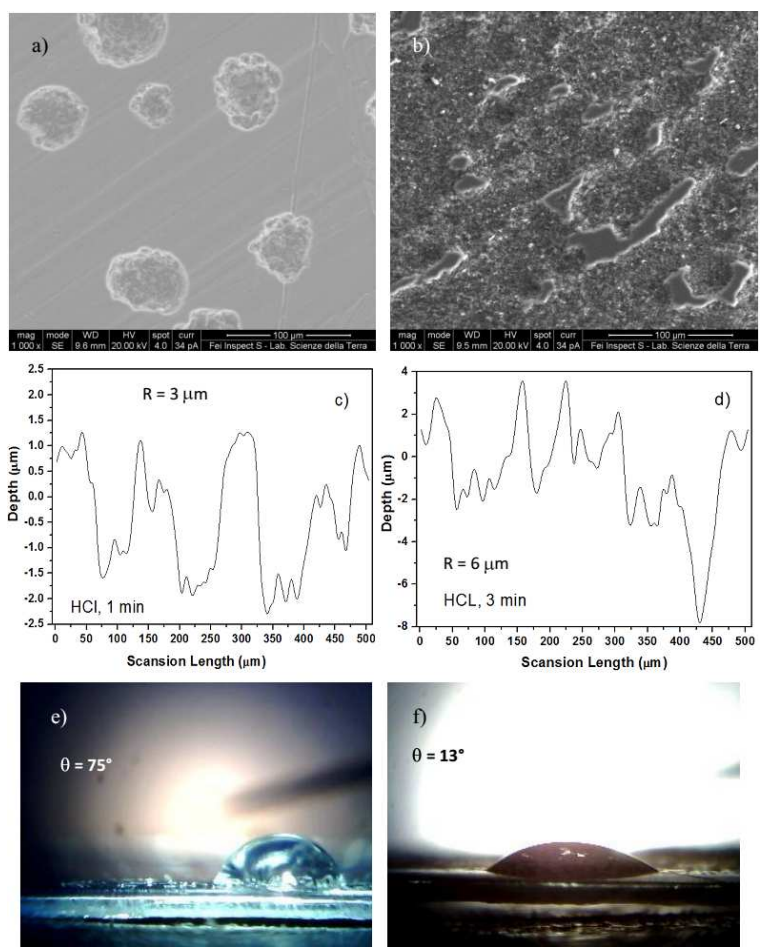

Fig. 3. Typical SEM image obtained for chemical $\mathrm{HCl}$ attack in the first $1 \mathrm{~min}$ (a) and of its progression at $3 \mathrm{~min}$ (b), surface roughness profile at $1 \mathrm{~min}$ (c) and $3 \mathrm{~min}$ (d) and measurement of contact angle for attack at $1 \mathrm{~min}(\mathrm{e})$ and $3 \mathrm{~min}(\mathrm{f})$.

produces hydrophilicity of the Al surface.

Ion implantation treatment. $\mathrm{Ar}^{+}$ions accelerated at $2 \mathrm{keV}$ energy and emitted from an ion gun with a current density of $20 \mu \mathrm{A} / \mathrm{cm}^{2}$ have been employed to irradiate in high vacuum, at $45^{\circ}$ incidence angle, the surface of the pristine $\mathrm{Al}$ surface for different times accumulating different ion doses, from $10^{14}$ ions $/ \mathrm{cm}^{2}$ up to $10^{16}$ ions $/ \mathrm{cm}^{2}$ [10]. For normal incidence the ion range is $44 \AA$ with a straggle of $19 \AA$, as reported in the SRIM simulation of Fig. 5a, and the energy transferred to recoil atoms is maximum at the target surface where it assumes a value of about $40 \mathrm{eV} /$ ion $/ \AA$, and decreases of about one order of magnitude at about $65 \AA$ depth, as reported in the SRIM simulation of Fig. 5b. At $45^{\circ}$ incidence angle the sputtering yield of $\mathrm{Al}$ surface is 4 atoms/ion and the average energy transferred is about $20 \mathrm{eV}$. Thus ion implantation removes atoms from the $\mathrm{Al}$ surface, especially at high incidence angle $\left(>45^{\circ}\right)$; generally it reduces the roughness of the Al surface and increases little the contact angle of the implanted surface as a function of the implanted dose, similarly to a polishing effect. Figure 5 shows the roughness profile of the implanted surface at a dose of $10^{16}$ ions $/ \mathrm{cm}^{2}(\mathrm{c})$, of about $0.08 \mu \mathrm{m}$, and the optical image of the wetting ability measurement indicating an angle of $96.5^{\circ}$ (d).

Treatment with metallic nanoparticles. Metallic nanoparticles of $\mathrm{Ti}, \mathrm{Cu}, \mathrm{Ag}$, and $\mathrm{Au}$ have been prepared via laser ablation in water for different applica- 

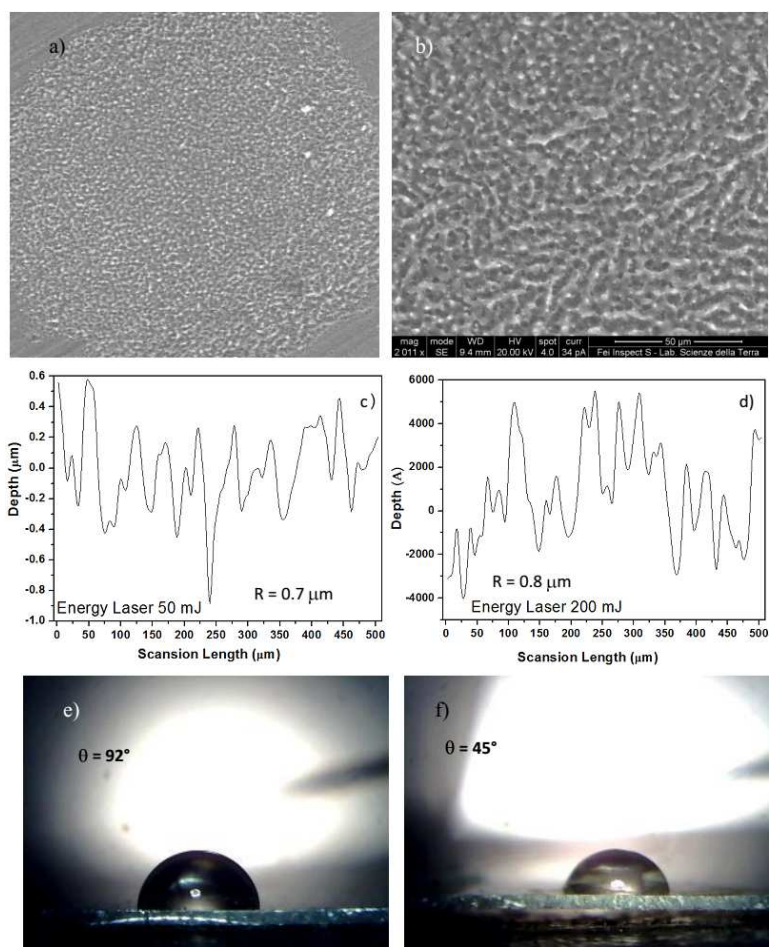

Fig. 4. SEM comparison of the laser ablated surface due to 50 laser shots at $50 \mathrm{~mJ}$ (a) and $200 \mathrm{~mJ}$ (b) pulse energy, corresponding surface roughness at low (c) and high energy (d) an optical images of the drop wetting ability for the low energy (e) and high energy irradiation (f).

tions $[11,12]$. The concentration of the prepared solution containing the nanoparticles was $5 \mathrm{mg} / 10 \mathrm{ml}$. The average dimensions of the produced nanoparticles was in the range 50-100 $\mathrm{nm}$, according to the visible absorption measurements of the produced solution performed in our laboratory and according to the literature data [13]. Drops of solution were deposited on the $\mathrm{Al}$ pristine substrate and left to dry. After $24 \mathrm{~h}$ drying, nanoparticles remain deposited on the pristine Al surface, as SEM images of Fig. 6 demonstrated for $\mathrm{Ti}(\mathrm{a}), \mathrm{Cu}(\mathrm{b}), \mathrm{Ag}$ (c), and $\mathrm{Au}(\mathrm{d})$. Successively the wetting was performed. The wet ability becomes function of the used nanoparticles as confirm the optical images reported in Fig. 6 for $\mathrm{Ti}\left(\mathrm{a}^{\prime}\right), \mathrm{Cu}\left(\mathrm{b}^{\prime}\right), \mathrm{Ag}\left(\mathrm{c}^{\prime}\right)$ and $\mathrm{Au}\left(\mathrm{d}^{\prime}\right)$ indicating a contact angle of $67^{\circ}, 91^{\circ}, 37^{\circ}$, and $53^{\circ}$, respectively. Thus, in general the nanoparticles decrease the water absorbance as a function of the substrate nature, as obtained for $\mathrm{Ti}(-36 \%), \mathrm{Cu}(-4 \%), \mathrm{Ag}(-61 \%)$ and $\mathrm{Au}(-44 \%)$.

In conclusion, the measurements demonstrated that the wetting ability of $\mathrm{Al}$ surface may be increased as a function of the kind of treatment at which it is submitted. Moreover, the roughness of the surface is a crucial parameter that controls the contact angle. High wetting ability is obtained using liquids containing nanoparticles and depositing NP on the investigated surface. Surface treatments based on laser irradiation, sandblasting and chemical etching, as a function of the time surface treat-
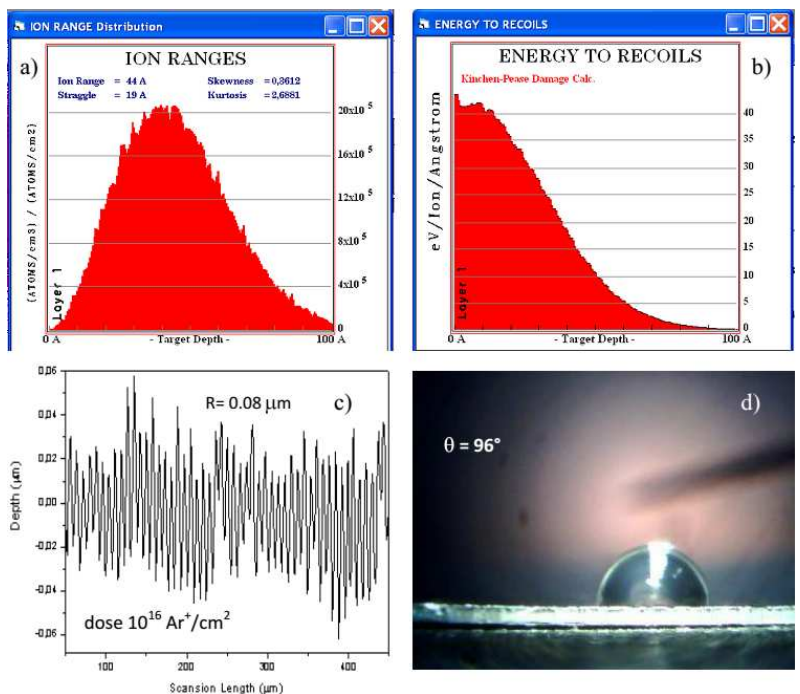

Fig. 5. SRIM simulation for the $\mathrm{Ar}^{+}$ion range in $\mathrm{Al} \mathrm{(a)} \mathrm{and} \mathrm{for} \mathrm{the} \mathrm{energy} \mathrm{transferred} \mathrm{to} \mathrm{recoil}$ atoms (b), roughness profile of the implanted surface at a dose of $10^{16}$ ions $/ \mathrm{cm}^{2}$ (c), and the optical image of the contact angle of $96.5^{\circ}(\mathrm{d})$.
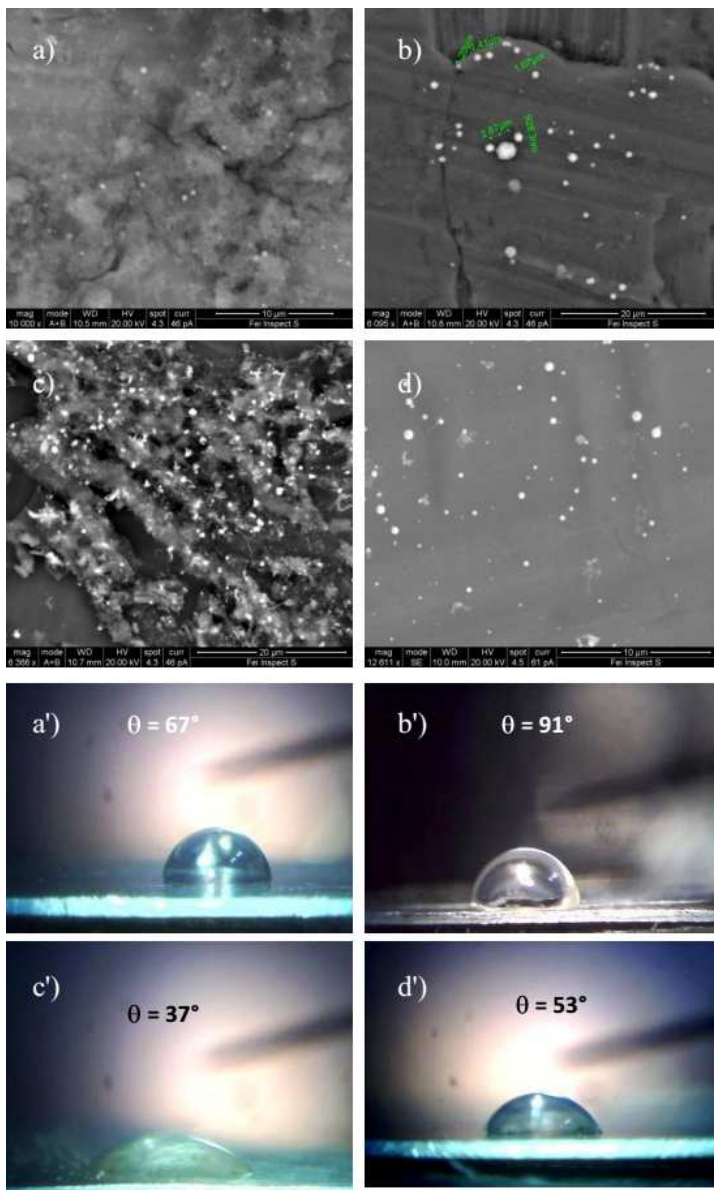

Fig. 6. SEM images of nanoparticles of $\mathrm{Ti}(\mathrm{a}), \mathrm{Cu}(\mathrm{b})$, $\mathrm{Ag} \mathrm{(c)} \mathrm{and} \mathrm{Au} \mathrm{(d)} \mathrm{deposited} \mathrm{on} \mathrm{aluminum} \mathrm{and} \mathrm{contact}$ angle measurements for water on the Al surfaces covered with $\mathrm{Ti}\left(\mathrm{a}^{\prime}\right), \mathrm{Cu}\left(\mathrm{b}^{\prime}\right), \mathrm{Ag}\left(\mathrm{c}^{\prime}\right)$ and $\mathrm{Au}\left(\mathrm{d}^{\prime}\right)$ nanoparticles. 

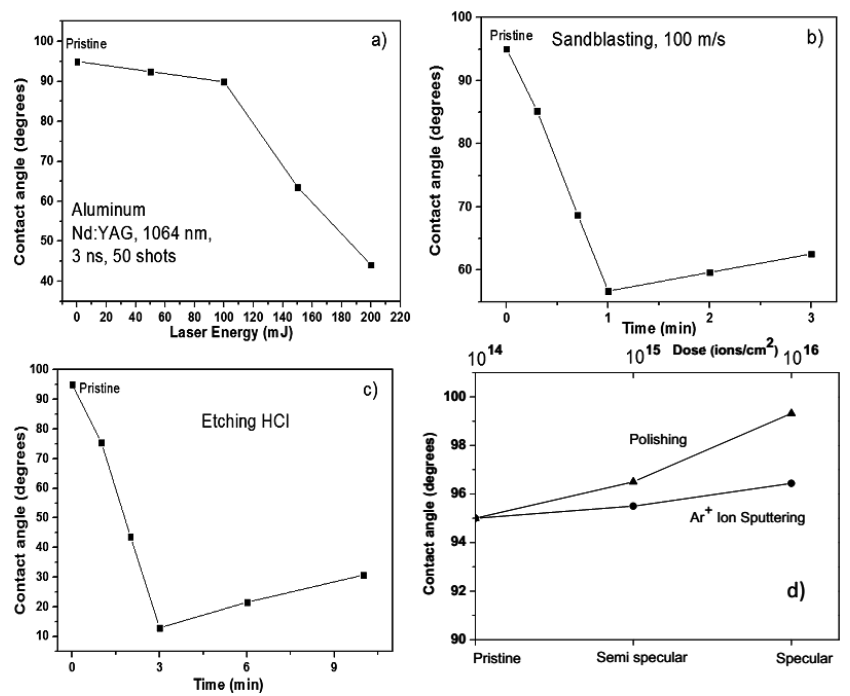

Fig. 7. Contact angle of the Al surface treated with 50 laser shots as a function of the laser energy (a), with sandblasting vs. time (b), with $\mathrm{HCl}$ etching vs. time (c) and with polishing and ion sputtering vs. ion dose and of type of treatment (d).

ment, demonstrate that the wetting ability of the surfaces increases, as reported in the summary plots of Fig. $7 \mathrm{a}-\mathrm{c}$, respectively. Low wetting ability, i.e. hydrophobic surfaces, are obtained using surface mirror polishing and ion sputtering, as reported in the summary plot of Fig. $7 \mathrm{~d}$.

\section{Discussion and conclusions}

Six different methods for creating controlled microscale morphology by varying the Al surface roughness have been presented, and the effects of these surface features on wetting and droplet retention have been quantified. Results show that the contact angle of water on aluminum is a function of the kind of surface treatment used and of the roughness produced. A summary of obtained

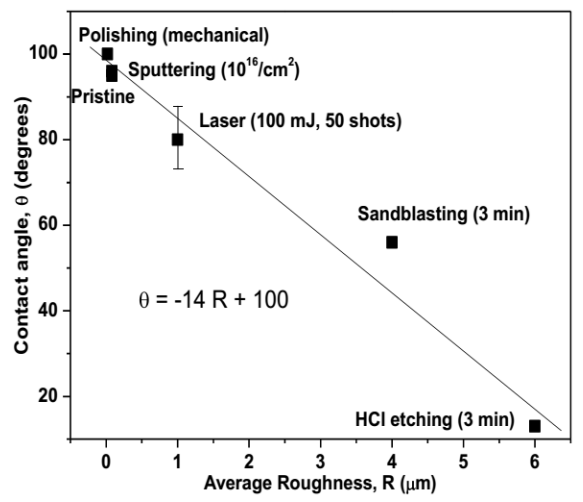

Fig. 8. Contact angle as a function of the average roughness for different methods of Al surface treatments and empirical relation between the two parameters.

results is observable in the plot of Fig. 8 reporting the contact angle as a function of the roughness for different methods of $\mathrm{Al}$ surface treatment, going from polishing, inducing low roughness and high hydrophobicity, to $\mathrm{HCl}$ etching, inducing high roughness and high hydrophilicity. In other words the contact angle, $\theta$ (degree), using opportune treatments, is approximately linearly dependent on the average roughness, $R(\mu \mathrm{m})$, according to the empirical relation

$$
\theta^{\circ}=-14 R[\mu \mathrm{m}]+100 .
$$

This linear trend was obtained with measurement with errors within about $15 \%$. Aluminum surface can be well-prepared for efficient wetting, coating and durability. Coatings of $\mathrm{Al}$ surfaces provide the most important pre-requisite for durability, if they are completely spread on the foil surface. Since the surface of aluminum acts as a barrier in a laminate, migrating compounds can enrich or react there. In this sense the hydrophobicity enhances the durability of the aluminum sheet. Plastic, ceramic and metallic coatings can be well adherent to the Al substrate if treatments increasing the wet ability are previously employed.

The techniques presented in this paper have broad applicability for metals other than aluminum, and their accompanying effect on wettability is of special relevance in applications concerning the $\mathrm{Al}-\mathrm{Al}$ welding and $\mathrm{Al}$ /fuse interface preparation.

High roughness of Al surface and porous structures induce high wetting ability, thus a liquid can penetrate very well inside the microcavities and the Al surface can result well adherent to other materials while very polished surfaces showing a minor contact area induce low liquid absorbance and material do not adhere to coverage films reducing eventual diffusion of elements through the interface. In this last case hydrophobic property characterize the prepared Al surfaces increasing the contact angle to about $100^{\circ}$. All the presented treatments are simple, not expensive and can be applied with successfully to control the morphology and the physical-chemical characteristic of the Al surfaces.

\section{Acknowledgments}

Authors thank Dr. G. Sabatino, Dr. M. Cutroneo and Mr. G. Ceccio of Physics Department and SdT of Messina University for useful assistance given with SEM and laser preparation of nanoparticles. Thanks to Mr. C. Marchetta and Mr. E. Costa of INFNLNS of Catania for the assistance during Al substrate preparation.

\section{References}

[1] Handbook of Aluminum, Physical Metallurgy and Processes, Eds. G.E. Totten, G.S. MacKenzie, Vol. 1, USA 2003

[2] J.E. Hatch, Aluminum: Properties and Physical Metallurgy, American Society for Metals, Metals Park Ohio 1984.

[3] A.J. Klinter, G. Mendoza-Suarez, R.A.L. Drew, Mater. Sci. Eng. A 495, 147 (2008). 
[4] C. Scolaro, L. Torrisi, M. Cutroneo, L. Velardi, J. Physics: Conf. Series 508, 012030 (2014).

[5] J.F. Ziegler, Nucl. Instrum. Methods Phys. Res. B 219-220, 1027 (2004).

[6] L.E. Samuels, Metallographic Polishing by Mechanical Methods, 4th ed., ASM International, Materials Park, USA 2003.

[7] L. Slatineanu, S. Potarniche, M. Coteata, I. Grigoras, L. Gherman, F. Negoescu, Proc. Manufact. Syst. 6, 69 (2011).

[8] H. Oh, J. Lee, H. Ahn, Y. Jeong, N. Park, S. Kim C. Chi, Mater. Sci. Eng. A 449-451, 348 (2007).

[9] A. Picciotto, L. Torrisi, A.M. Mezzasalma, E. Amato, C. Gentile, in: Proc. PPLA2003, Messina (Italy), Eds. S. Gammino, A.M. Mezzasalma, F. Neri, L. Torrisi, World Sci. Publ., Singapore 2003, p. 191.
[10] O. Gautsch, The Sputtering of Aluminum Oxide by Argon Ions, Joint Research Centre, Brussels 1993.

[11] V. Piriyawong, V. Thongpool, P. Asanithi, P. Limsuwan, Procedia Eng. 32, 1107 (2012).

[12] L. Torrisi, M. Cutroneo, G. Ceccio, Phys. Scr. 9, 015603 (2015).

[13] Nano Composix Europe, Chicago (2014), nanocomposix.eu/pages/ gold-nanoparticles-optical-properties. 